\title{
Mobile Devices in supporting members' participation to Village Community Banks: The Design Thinking Approach
}

\author{
William Clifford Gomera \\ Accountancy Department \\ College of Business Educationn \\ (CBE) \\ Dar Es Salaam, Tanzania \\ c.gomera@cbe.ac.tz
}

\author{
George S. Oreku \\ Open University of Tanzania (OUT) \\ Faculty of Science Technologies \& \\ Environmental Studies (FSTES) \\ Dar Es Salaam, Tanzania \\ george.oreku@out.ac.tz
}

\begin{abstract}
Village Community Banks (VICOBA) and mobile phones have become assistance to many rural societies in encountering financial problems. However, mobile phone usages to VICOBA are isolated resulting to unsubstantial benefits that do not foster member's participation. The weak participation of members to Village Community Banks activities has been one of the major impediments to their success despite of owning of mobile devices to some members.

The paper applies design thinking approach to explore the situation through identifying the deficiency available in mobile devices to VICOBA microcredit programmes in enhancing member's participation and suggest the effective usage pattern

The study captured 7 groups of village community banks at Ndungu village with total of 70 members whereas 48 female and 22 male participants. The study employed interview, observation and focus group discussion for data collection. Content analysis and coding approaches was used to analyse data and interpreting findings.

The findings observed that, there is a big potential in mobile phone use to village community banks activities and explicitly linking between design thinking and the qualitative data collection methods in inception phase of design process has been perceived to exist.
\end{abstract}

Keywords - Village Community Banks, Microcredit Services, Mobile Devices, Design Thinking

\section{INTRODUCTION}

Microcredit is a vital tool for poverty alleviation all over the world especially in developing countries. Microcredit Programs (MCPs) are considered as one of the effective tools to alleviate poverty in developing countries [1]. These programs introduced to targeted mostly resource limited societies that can conduct business and other productive activities [2]. Moreover, improving access of formal and informal credits by low income earners is a key point to boost development as it enables large base of population to involve in different activities like agriculture, small business and small scale manufacturing which improves living standards [3].

As for other Developing countries, Tanzanian Government is tremendously conscious about poverty alleviation, where Village Community Banks (VICOBA) found to be one of the partners on the move [4]. Since, VICOBA have tried to fill the financial gap to low income earners, active participation of members to these institutions is an important aspect to be addressed by practitioners and research world. Large part of low income earners communities in developing countries depends on informal credits where most of them are group based microcredits institutions like VICOBA. Informal microcredit providers remain strong financial sources to poor whom do not have access to either formal or semi-formal (microfinance) sectors [5].

VICOBA are member - based microcredits institutions which owned and run by members for members [6,7]. These groups are voluntary formed to target members after awareness campaign. [7]. Initiators and other NGOs are providing technical skills to group members through training in regular meetings. Training offered based on credit and savings, reporting and operating guidelines, leadership, conflict resolution, rules and regulations, business and basic financial literacy [6]. VICOBA operate by asking member to save money before taking loan at low interest rate. The loan taken starting with low amount and increase as borrower properly paying the previous loan.

Also members needed to attend regular meeting scheduled for specific interval of period mostly weekly basis. This affect the attendance and members' participation due to difficulties in attending the meeting [6, 7], hence affect members participation in VICOBA [8]. However, there is weak participation of members to VICOBA microcredit services due to time constraints and geographical distance factors. There are reasons which impede members' participation on VICOBA microcredit programmes especially of their regular meetings [9]. Some of the reasons are; low level of education to some of members, limited access to information, less mobility, busy schedules to members [7, 8]. Members' participation can be enhanced if and only the challenges affects their participation will be addressed.

On the other hand mobile technologies have been realized by researchers as one of the potential tool to address the identified challenges $[9,10,11]$. Mobile technology is a powerful tool to address social challenges and change a fate of poor people. Moreover, mobile device has being identified as a development tool that can easily address the geographical and time constraints [12]. 
Due to the penetration of mobile phone and its usage to almost people of all classes, the communication has increased its pace despite of the distance. From farmers to business personnel, mobile phone provides users with information when needed. Moreover mobile phone offers a greater scope in reaching people in town and rural areas. It has improved accessibility to information and enhances mobile services which in turn are instrument on bringing a chance in daily life [3].

There are number of literature focus on mobile phone usage pattern even to rural areas [4], ways members of VICOBA can benefit from mobile phone usage $[13,14,15$, $16,17,18]$ and the benefit that can be derived to enhance full participation on VICOBA activities [19, 20, 21, 22]. However, there is limited information that addresses poor participation despite of the usage of mobile phone in VICOOBA activities.

Care should be taken to conclude that usage of mobile phone is sufficient and can enhance activities and services of any group of people. The uses of mobile phones to practical activities at the grass root level need to be explored to find out if are sufficiently by itself. This calls our interest as researchers to find out deficiency existing in mobile device usage to enhance members' participation to VICOBA microcredits services. Thus we may also find out the effective use of mobile devices to enhance that member's participation.

It is the focus of this study to explore deficiency available in using mobile devices to VICOBA microcredit programmes in enhancing members' participation and suggest the efficiency usage to these microcredits institutions. Exploration of the subject matter needs involvement, collaboration and envisioning of the ideas. This attracts the usage of design thinking as it focuses both to human centric, environmental centric, knowledge and practises through explore on-hand and early participatory contribution of the design process [23, 24, 25, 26, 27, 28]. Therefore, objective of our study is to investigate deficiency on usage pattern of mobile devices to VICOBA microcredit services in enhancing members' participation and potential approach for effective usage in rural Tanzania context. The study objective were achieved by researching to the following guiding questions

\section{RQ1: What are the perceptions of members in VICOBA} microcredits services?

RQ2: What are the deficiencies of mobile devices usage in VICOBA microcredit services that affect members' participation?

RQ3: How mobile phone can effectively use to enhance members participation in VICOBA microcredit services?

This study attributes to the recent broad circulation and usage of mobile technology as the technology open up door of opportunities to informal microcredit groups. The establishment of the current usage pattern and identifying challenges thereon will pave the way for future studies and practitioners to find out solutions the practical solution.

\section{LITERATURE REVIEW}

\section{A. Microcredits to resources limited societies}

Microcredit services in developing countries are still young, small and limited especially in resource limited societies [29]. Most of low income earners are not aware of the service structure offered by Commercial Banks and how should use the facilities to establish their business and conduct different projects [30]. In addition, services in commercial banks are still limited to those customers who can afford collateral based loans.

Therefore, group based microcredit services are playing a very important role to cover the financial services gap that left by formal financial institutions. Members of microcredits institutions at their grass root level identify and utilize opportunities and resources in the sustainable manner that could not be achieved if forced could come from above [6, 20]. Moreover, low income earners perceive informal and semi - formal microcredits institutions, the most accessible source of capital while loan from formal banks are ranked as the least accessible financing alternative [31]. In this social condition some Microcredit institutions especially VICOBA in Tanzania are of great support of savings, loans, investing and social assistances for low income earners.

A Number of researchers have raised their motive to study different aspects of community microcredit institutions including VICOBA. There are studies have cantered been on limitation that hinder these institutions as pointed out by number of researchers as summarized in Table 1 below.

TABLE I. SUMMARY OF LITERATURE ON LIMITATIONS OF MICRO CREDITS INSTITUTIONS

\begin{tabular}{cl}
\hline I & More conscious about making profit [32]. \\
\hline II & Lack of financial resources to provide sufficient loan \\
& {$[33]$.} \\
III & High interest rate $[34,35,36]$. \\
IV & The administration section MCIs is not fit for purpose to \\
& communicate with clients after providing loans because \\
& of profit [37]. \\
V & $\begin{array}{l}\text { Rarely riches to extreme poor [3, 37]. } \\
\text { VI }\end{array}$ \\
Rarely organize training and development programmes \\
VII & $\begin{array}{l}\text { Some institutions take long time to approve the loans } \\
\text { [34]. }\end{array}$ \\
VIII & $\begin{array}{l}\text { Microcredit has limitation women accessing in their } \\
\text { scheme [10, 30]. }\end{array}$
\end{tabular}

B. Microcredit Programme of the Village Community Banks

By 2011 was reported that 723 Micro-finance Institutions currently have 190,135,080 clients all over the world and $81.7 \%$ of them are extreme poor and 104,694,115 are women clients [3]. Tanzanian based research group reported that Micro-finance institutions playing an important role for poverty alleviation in Tanzania [4]. Some researchers also have pointed out some challenges facing these institutions on servicing their customers [6, 8, 9]. However, other researchers have pointed out different approaches on dealing with challenges affecting microfinance institution based on their types. As indicated that some microfinance institutions are business based and some are members oriented (community) based kind of financial institution, some are formal and others and informal [16, 39, 40, 41]. 
In Tanzania, VICOBA and other informal financial institution have reached $27.9 \%$ of resources limited societies who have no access to formal bank services [4]. These institutes has almost 19 years of operation since their initiation in year 2000 by CARE Tanzania in Zanzibar and later on Orgut, SEDIT, World Vision and Women in Action (WiA) [40].

\section{Participation of Members in VICOBA programme}

It is important to know and move towards setting the position of low income earners in the society [3]. Low income earners play a key role in a private sector and micro, small and medium enterprises (MSMEs) in developing countries including Tanzania [42]. [19], suggests that low income earners directing up to $90 \%$ of their income to their family and communities. Moreover [22, 43], indicated their income are critical for food security as they cultivate up to $80 \%$ of food in many low and middle income societies. Also they play major roles in farm production and micro businesses; however, they remain constrained by financial challenges. Despite of forming large population of income generation, low income earners lack access to resources due to poor participation to microcredit activities, hence affect their rights to decision making [3, 44], this affect their participation on different financial activities [9].

Therefore, VICOBA's programme is promising to have future prospective, if challenges hindering members' participation in VICOBA activities will be addressed [4]. There is a need of essential strategy to improve status and participation in VICOBA programmes [45]. Some researchers in Tanzania have tried to answer positively how VICOBA potentially contribute to poorer in social, economic and financial inclusion and shown the extent of acceptance of VICOBA activities in the society [20, 21]. Based on [15], findings that economic empowerment can be achieved through resource ownership and full participation in different projects, full enjoyment of different services, receiving relevant and continuity training and receiving reliable and affordable information sharing. However there is a limit on the way members' participation of VICOBA activities can be enhanced.

\section{Mobile Phone to Rural Society}

There is no doubt on how mobile phones have proven to be a tool for economic growth; hence, investing this technology to low income earners can improve the overall well-being of families and communities $[11,46]$. Introducing activities of resource limited societies with the usage of mobile phones can accelerate social - economic development $[47,16]$ found that phone are the information related technology that has done the most to reduce costs, increase income and reduce uncertainty and risk through supporting the current realty of informal information, extend social and business networks and clearly substitute for journey. Mobile phones connect people and provide them with information that is useful in daily lives [48]. Their usage goes hand in hand with faster economic growth, job creation and profitable business.

There is strong link between increase in mobile phone and faster economic and business development [17, 49]. Moreover, Tanzania is not different from many other African countries in terms of mobile usage. During exploration of this research it was realized that there is an increase of mobile phone subscribers in each quarter of the Years 2019 as per Communication Regulatory Authority report. Subscription has increased by 168,726 during the first quarter of the year with the trend of total subscription of 43827857 in January, 43,946,080 in February and 43,996,583 in March[56]. This kind of increase in subscription fosters the economic growth of the country and contributes to the national income eventually.

Despite the benefit of mobile phone connectivity to most of developing word like Africa, Asia and Latin America. Low income earner in these region are not benefiting as much as expectation. This is because there number of daily activities not tailor-made accommodated by mobile technology to support the real need of the low income earners.

However, as suggested in [50] this is an agenda to focus on so as to increase benefit of mobile phone usage among low income earners. First is to position the phone as a life enhancing and income generating tool. The aim here is to create innovative programmes to increase the uptake of mobile phone amongst low income earners. Second is to set a mobile phone to be an operating tool at international and local assistance, with the focus to promote the mobile phone as an effective development tool which creates international and local opportunities. All these will help to identify cultural relevant and acceptable ways of promoting mobile phone ownership [50].

\section{RESEARCH DESIGN}

The study applied design thinking to explore perception of members towards VICOBA microcredit services, deficiencies of mobile devices usage in VICOBA microcredits services that affect members' participation. Moreover, to find out an effective ways mobile devices can be used to enhance members' participation in VICOBA microcredits services.

\section{A. The Design Thinking}

This study formed part of the inspiration phase of design process to the VICOBA mobile microcredit application. This phase involve analytic sequence in which the designer determines the elements of problem and specifies possible solution [23]. The design thinking has gained popularity on dealing with problems in different discipline like IT, Business, Education and Medicine [24]. This application has provided potentials to provide unambiguous design research answers of the challenges that face community of any level. With the same note this study applies the aspect brought up by [24], that focused on the core of Design Thinking and its contribution to practitioners in this case, members of informal financial groups.

The design thinking is important in this context due to its capability of fixing the scientific basis that the design does not lie and its concern on connecting and integrating the usefulness of knowledge, practices and arts, in a ways that are suited to the problems solving and intended purposes. Under design thinking, designers are exploring concrete integrations of knowledge that combine theory with practice for appropriate productive purposes, hence turn its importance to technological innovation [23]. Therefore, through design thinking, our study drafted the innovative solution by considering the fundamental reasoning pattern behind the practical aspect, theoretical consideration, and then connecting with the core design practices of framing 
and innovation. The paper ends with presenting appropriate way designers can connect the practises of low income earners, theoretical background of discipline and the technological innovative ideas in bringing up the practical solution to the challenges affecting practitioners.

Design thinking is the core creative process structured around a series of in-depth knowledge base and case studies practitioners and work of outstanding designers supported by interwoven analysis. The range covered reflects the breadth of design based on evidence from observation and investigation of design practice [25]. Design process under design thinking start with preparation process, which involves focusing on relevant aspect. This phase assessment and elaboration the practical problem to mark a sense for proposing the solution. These include Data and observations of the situation coming from the design environment, such as feedback from experience faced by practitioners. Moreover, the practise has to strongly connect with appropriate discipline [26].

The design thinking applied in this study involved overlapping spaces of inspiration, ideation, and implementation. Inspiration focused on problem that motivates the search for solutions; ideation as the process of generating, developing, and testing ideas; and implementation as the path that leads from the project stage into people's lives. The inspiration phase provided a starting point of the design project and a set of objectives to be realized basing on people's needs are [26, 27].

As proposed by [27] and [28] that the best ways of doing this were through interview, focus groups, observation and surveys. However, to yield deep insights, these techniques were used in line with conventional aspect to point toward incremental improvements. Observation was one of the methods since people often can't tell us what their needs are, their actual behaviours can provide us with invaluable clues about their range of unmet needs [27, 28]. A better starting point of our project was to go out and observe the actual experiences of interaction between VICOBA and their members. Doing this gave further insight into the practices.

\section{B. Research Method Used}

We used qualitative research approach due to our focusing on exploring the situation and requirement of detailed information that assisted in establishing a base on the perception, usage and deficiency thereon [51]. The explorative and interpretative approaches used due to the fact that the researcher wanted to make sense of words from human action [52].

Qualitative study fits the design thinking and found useful to information system because it started on identify human behavior toward technology [26, 27, 53]. The interactive approach of practitioners and researchers has also been used in conceptualizing the practical solution of the challenges hinder members' participation on VICOBA activities. The explorative study made a base for designing thinking (DT) aiming on finding practical solution of the existing practical problem of the mobile devices usage fail to enhance members' participation on VICOBA microcredit services [12]. We collected qualitative data i.e. situation explained through words although, few numerical collected to show number of people events and percentage. These numerical also were presented in the study report. However, our explanation still base on qualitative kind of the study.

\section{Data collection methods}

Data collection methods included interview, observation and Focus Group Discussion (FGD).

a) Interview: We used interview as it is usefully in the interpretive studies [47] that focus on the way members using mobile phone to receive microcredit services from VICOBA, deficiencies thereon and opinion on the way forward. Moreover, through interview individual perception and opinion on VICOBA operations, benefits and way forward were explained. We interviewed 30 members out of 70 of the entire study. Selection of 30 members out of 70 was done randomly by researcher. Specific and planned appointment made with interviewee was made to make sure that interviewee was comfortable with the schedule. Interview session lasted for 15 to 25 minutes, depending on the respondents' openness and awareness of VICOBA and technological opportunity available. Researchers structured the interview question in such a way that interviewee could give explain how the mobile devices used in VICOBA activities to enhance participation. This was done purposely based on the study conducted by (Joseph, 2011). During interview researchers took notes, however for more understanding the interview process conducted in Kiswahili.

b) Focus Group Discussion: The FGD was used as extension of interview that allowed participants to have wide explanation on the topic. Here participants shared experience on mobile phone usage, deficiencies of mobile phone usage that affect members' participation in VICOBA. Selection of study groups based on willingness of leaders and members participation to the study. There were 7 groups of 10 participants each, with average of 8 female and 2 male. Selections of participants were member nomination that made during weekly meeting. Nomination of participants made by members themselves based of representation of occupation criteria i.e. employees, business personnel and farmers. Researcher took notes for every member's contribution; moreover, Kiswahili language was used during discussion. This helped members to talk free and fluently since Kiswahili is a Tanzanian is a National language. The FGD used by researcher as team of researcher and practitioners to conceptualize on the practical problem and think on the potential practical solution. This formed a base of DSR that involve participatory approach.

c) Observation: We applied observation during weekly meetings in order to see the proportion of members and attendance on meeting. Observation method used to find invaluable information that could not be told [27, 28]. This method used due to the fact that researchers had time to attend those meetings as observers. Also researchers took notes on the way members behaved in meetings, their contribution, and ways they respond to or asked questions. Here researchers were complete observers of what was taking place. Researcher recorded data through handwriting of things taken place during meeting without audiotaping and by videotaping. The 
observation of each VICOBA group was also important to see if there was a different in approach from one group to another.

\section{Area of Study}

The case of Ndungu village in Same District of Kilimanjaro region, northern part of Tanzania was selected as area of study. The reasons for selecting this area was; familiarity of researchers with residents of the village this provide chance to get detailed information from participants. Second, its nature and characters of people in this area proposed to be good representative of other villages in developing countries concerning VOCOBA programmes. Third, constraints faced by VICOBA members in this village resemble other developing countries in terms of formal financial institution support.

\section{E. Participants}

Participants of the study were 70 members selected from seven VICOBA in Ndungu village. These groups are; Yongoma Group, Mwamko Group, Amkeni Group, Jitegemee Group, Sasa Kazi Group, Juhudi Group and Changamkeni group. The reason for limiting number of groups was to limit the size of research being a detailed analysis. With 7 selected VICOBA groups seemed to be useful due to the complexity of the study that need in-depth study of three variables i.e. VICOBA activities, members participation and current pattern of using mobile phone in VICOBA activities and challenges thereon [12]. Data Analysis

We used thematic analysis whereby respondents' ideas were grouped into different themes. This done initially by coding the questions into different groups and posing each explanation against each established code. All data obtained during interview, FGD and observation were recorded against pre-established themes that focused on usage pattern, deficiencies and opinion of the way forward in using mobile phone in VICOBA to enhance members' participation. After forming general categories, data coded and grouped into small related units, which were then categories into related themes for each group. The common concepts appeared in each discussion were noted to make group of idea, hence come up with items of the results and discussion of the study

\section{FINDINGS}

The study involved three variables; members' participation, VICOBA microcredits services and usage of mobile devices. It was revealing that, the insight of members' participation on VICOBA microcredit services through mobile devices could make a significant change to people's life.

\section{A. Description of Participants}

Participants were 48 female and 22 male that involved in productive activities like; farming, micro-business and teachers of primary and secondary school. Some of microbusinesses owners dealt with food stuff, small shops and sell of other basic need items. About $60 \%$ of participants were of standard seven level, $22 \%$ form four, $14 \%$ certificate and diploma level, $4 \%$ degree level.

\section{B. Services offered in VICOBA Microcredits Programme}

We found that most of VICOBA members opted for the microcredit programme that fit them; hence there is no constant programme for all VICOBA. However, in general the following microcredits programmes have almost available to all groups except minor deviation. We found that most of VICOBA microcredit programmes are conducted in their weekly meetings. Services offered to members include; savings, loan, training and business networking.

Researchers found that, the main programme of VICOBA is to assist member to increase savings, provide members with loan, provision of training and members networking for marketing and supplies.

There different kind of savings found in this study. These savings are received on weekly basis that collected from members in form of; contributions (wekeza), and social funds (huduma kwa jamii). Also entry contribution know as initial share (hisa anzia) which paid by member to join VICOBA. We also, found that funds contributed used in provision of loan at low interest rate, help VICOBA members who are in need and used in operation activities. Loan given without collateral, since, contribution, and community knowing each other is enough to provide loan to a person in need.

For the training, we observed that VICOBA invite different professionals to equip members with basic skills on loan, business management, food process and preservation and production of local products like soap. This help to equip VICOBA members with knowledge of different aspects on finance, business and productive activities as most of characteristics of VICOBA members are of low education and people that doing micro business and small scale farming for the family welfare.

Business networking was observed to be very another important service offered by VICOBA as the members are allowed to come with different services and products during weekly meeting. Also it provide forum for suppliers and consumers to meet and exchange product. Moreover give chance for business opportunities after meeting. Member argued that VICOBA microcredit programme is less cost, managed in a voluntary bases with minor cost been taken care by members themselves. It can be assessed by all poor at the grass root, since share value of VICOBA is planned by group members themselves. Also the bottom up approach decision making, planning, implementation and ownership in the model of operation used.

We found that some of VICOBA have no any other services than financial service. Some respondents expressed their feeling in focused group that services provided by these institution should not be limited to financial services only, instead should include services like training, market information and business networking.

\section{Importance of VICOBA to members}

From data collected the study found that microcredits play a significant role to member. We found that $47 \%$ of members that participated in the study use funds from VIKOBA for business and farming, $22 \%$ of them uses school fees for their children, $20 \%$ uses to improve living standard and $11 \%$ uses for different purposes. Although, all respondents agreed to benefit from VICOBA, there are different uses of money received from VIKOBA. The statement can be backed up with the evidence from table 2 below which shows how they have being benefited in different ways. 
Moreover loan provided to members after soliciting funds from savings are collateral free. The loan was given at very law interest of $3 \%$ to $10 \%$ depending on the decision of group members. The interest income received from loan advances benefiting all members of the group depend on the amount of shares contributed by a particular member. Participants of the study envisaged that, VICOBA microcredit programmes is one of the better tool for community emancipation socially and economically in Ndungu village.

This is evidently proven by members who claimed to benefit from resource mobilization process at the group level and benefited with the training programme and business networking at individual level during group meetings. Our study confirmed that VICOBA have large impact to their members. The information received from the study indicated that VICOBA members contribute little amount of money each week (most of them is the balance after house hold consumption) then after a certain period of time receive loan from VICOBA savings without collateral.

VICOBA microcredit programme have positively contributing to member development and economic growth by improved quality of life and social wellbeing. Also, this scheme has enable member to build up their awareness, knowledge, skills and capital generated from within themselves. Furthermore, members participated in this study admitted that their financial situation improved as well as had better living condition. Some members admitted that "through VIKOBA have being able to start their own small local shop to sell vegetables, fruits, and cooking needs. Hence assist to support family needs".

TABLE II

BENEFITS OF VICOBA TO MEMBERS

\begin{tabular}{|l|c|c|}
\hline Uses of loan advances & Frequency & Percentage \\
\hline Business & 33 & 47 \\
\hline School Fees items including & 15 & 22 \\
\hline $\begin{array}{l}\text { Buying house } \\
\text { furniture }\end{array}$ & 8 & 20 \\
\hline Other Uses & 11 \\
\hline
\end{tabular}

\section{Perception of VICOBA Services to members}

We were interested to find out the extent participants perceive the programme/ services offered by VICOBA. During group discussion participants expresses their opinions basing on their perceptions towards VICOBA activities. Most of group participants admitted that VICOBA programme are well known to them. This backed up with the argument that before joining the group a well training on how generally VICOBA operating is conducted. Moreover, some of participants have being members of VICOBA for years and know exactly how services offered.

We found that some of VICOBA do not provide services on time. This noted in some FGD that VICOBA microcredit services are not offered on time. The commonly mentioned services that do not often offer to VICOBA are training. This explained that it take long interval between training sessions, some are taking up to six months since the last training. For that case has being proposed to see how this service can often available to members as it is potential.

To some extent participants were satisfying with VICOBA microcredits programmes; however some mentioned issues that need attention. Some participants mentioned time foe meetings consuming time hence affect participation members. We confirmed poor participants of member on VICOBA activities due to; most members occupied with family and community services, low level of education, lack of leadership ability, experience and lack of confidence. Also some of members have very small number of shared that they are not qualifying for large loan which can enable them to start business.

\section{E. Deficiencies of mobile devices usage in VICOBA}

Most participants explained that their interaction with VICOBA through mobile devices is not of high quality due to the fact that usage of mobile devices has not substituted the need of physical. Physical contact has being identified to be cha contact that consuming time of most low income earner. Also they argued that the usage of mobile devices foe normal calls, short messages, mobile money services and online banking have not help the transparency of their savings and loan.

Moreover, it has identified by participants that mobile phone do not help member with sophisticated information of other services like. "We use my mobile phone for some of the microcredits services from VICOBA but there some important services that are not offered through these devices".

For already existing services like mobile money, we observed that the service help only sending money to VICOBA account or a person responsible for collections. However, the services do not provide balance of the savings or loan balance in an individual account. Therefore they argued that this service has no different with manual contribution of money because it can help the member to access his account without make a physical visitation to VICOBA secretariat.

For the case of short messages participants identified challenge that the method of information sharing is not consistence and sophisticated. This happened because it is not automated that a certain particular massage with be sent to members for a specific purpose rather most of these messages based on reminding members either to attend meetings or to make payment required.

Therefore, researchers decided to find out views from participants on the challenges face by members in using mobile devices in VICOBA microcredit programme.

The study found that in some points all members are using mobile devices in VICOBA activities. However, members identified number of challenges that are associated with usage of mobile devices in VICOBA microcredit services and hence affect members' participation. During FGD the participants identified these deficiencies as listed in Table 3 below.

TABLE I. DEFICIENCIES OF MOBILE DEVICES USAGE IN VICOBA MICROCREDIT SERVICES

\begin{tabular}{|c|l|}
\hline S/No & $\begin{array}{l}\text { Deficiency on mobile devices usage in VICOBA } \\
\text { microcredits programme }\end{array}$ \\
\hline 1 & $\begin{array}{l}\text { Failure of mobile devices to substitute weekly meeting } \\
\text { of VICOBA }\end{array}$ \\
\hline 2 & $\begin{array}{l}\text { Usage of mobile devices has not supported provision of } \\
\text { relevant information }\end{array}$ \\
\hline 3 & $\begin{array}{l}\text { Mobile devices usage has not enhance the frequently of } \\
\text { training provision to members }\end{array}$ \\
\hline
\end{tabular}




\begin{tabular}{|c|l|}
\hline 4 & $\begin{array}{l}\text { Mobile devices usage has rarely riches to extreme poor } \\
\text { especially women }\end{array}$ \\
\hline 5 & $\begin{array}{l}\text { The mobile devices usage have not enhanced the training } \\
\text { services to members }\end{array}$ \\
\hline 6 & $\begin{array}{l}\text { Poor communication between VICOBA leaders and } \\
\text { members }\end{array}$ \\
\hline 7 & $\begin{array}{l}\text { Lack of transparency of members' contributions, interest } \\
\text { earned and loan provided }\end{array}$ \\
\hline 8 & $\begin{array}{l}\text { Lack of timely report on the performance of specific } \\
\text { VICOBA }\end{array}$ \\
\hline
\end{tabular}

\section{F. Proposed usage of Mobile Devices to VICOBA}

Microcredit services

Participant positively responded to the interests of having effective ways that can reduce physical contact and substitute for frequent movements. During interview and focus group discussion participants suggested that VICOBA has to find ways that can minimize time spent on service deliverance and meetings. As they identify time and physical meeting affect the members' participants in VICOBA microcredit programme.

Furthermore they admitted that receiving services at any time anywhere will help them to participate in VICOBA activities at the same time dealing with their daily activities. The usage of mobile devices to receive services from VICOBA has attracted attention during FGD because most of participants claim to have bust schedule in their agricultural of business activates therefore they have no idle time to make follow up of microcredit programme.

Discussion on VICOBA mobile services took an interesting turn as participants admitted that they had no idea on the possibility of VICOBA to offer services to their members through mobile phone since they are not expert on how these services can be undertake. However, they argued that mobile devices has to target on minimizing time for weekly meeting, increase transparency, reduce time lead for services and being able to compensate for human movement and cost minimization.

Participant highlighted some of VICOBA microcredit service that can be offered through mobile devices hence to enhance members' participation. The identified services were financial services (money transfer, loan repayment and loan disbursement), training services, weekly report, members' status and business network service. Basing on these this requirement the researchers call an idea of researcher developing the Mobile application for VICOBA.

Participant went far to the point of identifying the basic characteristics of the mobile service tool. They expressed that technological tool to be built to have the following features: - friendly user interface, offered in Kiswahili, offered in all multimedia i.e. video, audio and document. They proposed that the tool should consider both rural and rural environment, nature and challenges of rural society and size of the mobile devices owned by most of rural people. Participants showed willingness to use mobile phone to receive services from VICOBA. Some commented that "If mobile phone will give chance to see balance, other information and training at any time anywhere it will be a value addition tool for members it may improve trust of members on VICOBA

\section{DISCUSSIONS}

This study was guided by set of research questions which were used to set the base of discussions. The following were research questions:

\section{A. RQ1: What are the perceptions of members in VICOBA microcredits services?}

From finding we confirmed that VICOBA microcredit programme uses direct management with the poor, and look to the individuals and their immediately needs, also helps community to generate economic growth through market driven business initiatives. On top of that, micro-credit decreases individualisation and create a synergy well-built for group of people to domination resources get liberated to run some of their needs independently. Also members receive financial and other resource ownership freedom for income generation. The study observed that access to micro loan at low interest rate without collateral improved selfsustainable, family support and increase resource ownership. It also confirmed that before joining VIKOBA most of the participants owned very few resources and some owned nothing, however through credits programme members can own assets and money deposited as shares in VICOBA.

The main beneficial of VICOBA microcredit program are low income earners. VICOBA, described as a model of micro-credit programs being; target to help extreme poor and their families to overcome poverty, provides collateral free loan. Loan proposals are sanctioned based on 'trust', mainly given for income gathering activities and small business development provide door-step banking services to the poor. That is why people do not need to go to the bank, bank will come to them, borrowers must join a credit union to get a loan, repayment is to be paid in weekly instalment, new loan being available to beneficiaries as soon as they repaid the previous loan, voluntary savings scheme whereby a certain amount deposited to the credit union for every specific period.

Research findings confirmed the findings from several studies made in Tanzania which showed that VICOBA microcredit programme has an exclusive impact on economic development of low income earners $[4,6,8,20$, 21, 39, 45]. Moreover, VICOBA programme support business initiatives and working close with poor people as pointed out by [54, 55], that, "Micro credits institutions represents a sea change in the way financial capital used to stimulate economic growth in developing countries".

We confirmed that members of VICOBA contribute their shares and social protection mostly on weekly basis, these contributions are of three types; initial shares ("hisa anzia" in Kiswahili), social fund ("huduma kwa jamii" in Kiswahili) and savings contribution ("wekeza" in Kiswahili). After three or four months of savings and contributions the study confirmed that VICOBA microcredits services of the groups participated in this study offer loans to support members' businesses and concur with services presented by [9]. For the first time members take short term loans of three months, later after gained competency in entrepreneurial skills they take long term loans of six months up to one year. Each loan is returned to the group basket with low rate of interest compare to commercial bank and formal financial institutions. These institutions enable members to mobilize savings, build capital, and receive training on how to allocate funds and expose them in business management skills. 
Moreover, they create chances of market network among members and building financial strength to the group and individual member of the group.

\section{B. RQ2: What are the deficiencies of mobile devices usage in VICOBA microcredit services that affect members' participation?}

Although, different studies pointed out challenges faced by most of VICOBA members in microcredit programme participation [55], our study wanted focused only on deficiencies on using mobile devices that affect members' participation. Our finding from participants confirmed that the services offered by VICOBA microcredit progamme are limited and not automated, hence affect members' participation.

We confirmed that members of VICOBA at Ndungu village had access to a limited number of microcredits services offered through mobile devices. Services offered through mobile devices are such mobile payments, calls, short messages and online banking. Our findings confirmed that more sophisticated microcredit services, such as mobile training, business network are some of alarming deficiency associated with the current mobile devices usage. The deficiency confirmed in our study indicated to affect members' participation in VICOBA microcredit programme.

Members, participation in VICOBA microcredit programme typically needed assistance of usage a sophisticated mobile devices application that can enhance the efficiency sharing of information among the players. We also confirmed that majority of VICOBA typically use mobile phone only for calls, short messages and money transfer. Additionally, there is high need of sophisticated platform that can assistance to increase number of services that can offered to reduce time and physical distance for VICOBA microcredit services.

Members seemed to be uncomfortable as using a mobile phone for microcredits services as there is no solution for a need of physical contact. Usage of mobile phone in VICOBA was more widespread in the villages members used mostly mobile money services, and almost exclusively for sending/receiving money. This is because relatively few rural Tanzanian had bank accounts reported accessing their money over-the counter in a bank instead of depositing or withdrawing funds by themselves at an ATM machine. However, lack of digital skills, unsophisticated number of services and lack of access to firsthand information were raised as reasons for discomfort using mobile technology. Consequently this resulted to heavy reliance on manual works for most of rural society.

\section{RQ3: How mobile phone can effectively use to enhance members participation in VICOBA microcredit services?}

From our findings we confirmed that there is a need to introduce a tool that can assist in service provision to facilitate VICOBA microcredit services. As we confirmed that most of services provided by VICOBA is limited to time and physical contact that affect members' participation. We confirmed that the current mobile usage in VICOBA are mainly on mobile calls, mobile money, short messages and some are online group savings. Normal calls used by VICOBA leaders to make follow up for meetings and request for weekly saving or loan repayment. Short messages used for information sharing, mobile money services for money transfer and online group savings is to make savings direct to group account maintained by commercial bank.

Despite of the high usage of mobile services, they proved not to motivate transparency and sophisticated information sharing. Therefore, calls for an attention of having a sophisticated system that can assist to provide online microcredit services programmes. Moreover, it confirmed that's usage of mobile devices to these programme will amount to increase number of services, data to be analysed, and sophisticated information and transparency.

Based on participants view it was revealed that technological application will encourage members to take position and participate in VICOBA programmes at large. Ubiquitousness of mobile technology and supervising tasks will save time and having automated operations will speed up the many activities which currently are done manually as observed by [54]. This will motivate members' participation in VICOBA microcredit programmes.

It was experimented that an effective use of mobile phone may bring a substitute to manual performance and information sharing. It is argued that, short messages that contain report will assist leaders to be transparency and provide regular report through posting data in system and send information to members. Also automated texting will save time, and effort of movement to find information.

Also argued that receiving training through mobile phone may save time, space required and enhance training continuity. As pointed out by $[9,4,56,57,58,59]$ that among other roles, one of the big role of VICOBA is capacity building through training, so leveraging on that will bring a very fruitful outcome to low income earners and under privileged group in the society $[56,57,58,59,60,61$, 62]. Moreover, members participated in the study propounded that there is a need to introduce means that may assist women to receive training remotely at any time.

\section{The link of quantitative data collection methods and design thinking}

This study has confirmed the importance of observation, interview and focused group in inspiration phase of design thinking. As it has argued that design thinking requires more involvement approach at the inspiration phase of the design process $[26,27,28]$. Therefore, this study proposes that the qualitative data collection method enhance the three main aspects to inception phase of design thinking. First, it is more involving in the big picture of social innovative design that helps to find detailed inputs from practitioners. Second, encourage collaborative effort where the design process is spread among diverse participating stakeholders and competences. This is confirmed through gained strong collaboration from VICOBA and their members. Third, it helps to envision the ideas through explored on-hand and early participatory contribution of the design process.

This study contribute to the design research community that the qualitative data collection methods can effectively be used in design thinking to save multiple perspectives and reach desired innovative picture of different practitioners. This is realised basing on the fact that the design thinking used qualitative data collection methods to understand the complex and puzzling VICOBA practices and connecting with particular discipline theories to realise the innovative need. This supports the aspect of design thinking of focusing 
on human and environmental centric aspect hence help to understand practices without first referring back to design challenges.

The members (humans) activities were established in different groups to know the unknowns practises. This create the 'what' aspect (the VICOBA activities and services in a situation we need to attend), through observation we established the 'how' aspect (VICOBA practices). This provides a room for design thinking to safely predict desired practice and requirement to address the explored practical challenge. The "what" and "how" translated connected with human centric and environmental centric aspects of the design thinking to explain the observed behaviour and activities to be performed in the innovative picture. The stage of establishing "what" and "how" in practical aspect helps to explain phenomena in design and other productive professions.

\section{CONCLUSION}

Contemplations need to be kept in mind when considering usage of mobile devices in financial products and services for rural population in Tanzania. From the study it was realized that poor members' participation in VICOBA caused by lack of sophisticated information sharing. However, efficient usage of mobile devices usage to VICOBA among people in rural Tanzania may increase as long as there are specific applications that have been customized to fit their needs. Mobile phones are already a fixture in the sampled areas in Tanzania and can boost up members' participation in VICOBA. However, new products and services should be imbedded in the mobile devices that may enhance the members' participation.

Off-the-shelf products, including VICOBA, are unlikely to reach and appeal to all members of the society in rural areas. Applications need to take into account services required by particular society. Tanzanian rural need help to effectively use of a mobile devices that will enhance their participation to VICOBA microcredit programme. Currently very few VICOBA services are associated with usage of mobile device, therefore to assist effective usage of mobile devices, researchers and software engineers have to consider coming up with application that can offered different services to members.

Our study paved way for future studies that may aim at coming up with a tailor-made application on VICOBA microcredits services. However the consideration of any application should take into account understanding level of rural society, services required, cultural of rural society and environmental setting of rural society. It should have a user approach development. Most of participants claimed to have basic knowledge on mobile phone operation, moreover admitted on limited participation to VICOBA microcredit programme. To focusing findings, the study proposes researchers to consider proper design procedures that help to use potentials that available in mobile technology to enhance members' participation to community groups. This study suggests future studies to consider humans activities of different groups to create value on the 'what' aspect through sophisticated the 'how' aspect.

\section{REFERENCES}

[1] L. R. Reed, "State of the microcredit summit campaign," in Microcredit summit campaign, Washington DC, 2011.
[2] M. Yunus, "Vision 2050: A Poverty Free World," The Journal of Social Business, vol. 1, no. 1, pp. 7 - 23, 2011.

[3] J. J. Mmasa, "Determinants of Smallholder Women Farmer Access to Informal credit in Tanzania. A case of Singida and Chamwino Districts," vol. 3, no. 2, 2017.

[4] B. Verhan, R. Magesa and S. Akidda, "Mushrooming Village Community Banks in Tanzania: Is really making a difference," International Journal of Innovation and Scientific Research, vol. 6, no. 2, pp. 127 - 135, 2014.

[5] B. Priva and P. Srivastava, "Scalling - up Microfinance for Indias Rural Poor," World Bank Policy Research Working Paper (WPS 3646), 2005.

[6] M. Ahlen, "Rural Member - Based Microfinance Institutions - A field assessing the impact of SACCOs and VICOBA in Babati district, Tanzania," Sodertorn University, 2012.

[7] G. N. Maleko, B. S. Liheta, D. Aikaruwa, A. Lukas and G. A. Sumari, "Women Participation in microfinance Institutions of Tanzania: The case of SAvings and credit cooperative societies (SACCOs)," Journal of Business Administration and Education, vol. 4, no. 2, pp. 139 $175,2013$.

[8] J. M. Muhoho and H. Mwinyimkuu, "To ascertain the contribution of the microcredit institutions in women poverty alleviation in Tanzania: The case of Kinondoni municipality, Dar es Salaam, Tanzania," International Journal of Innovation and Scientific Research, vol. 9, no. 2, pp. 410 - 419, 2014.

[9] P. M. Kato and J. Kratzer, "Empoering women through microfinance: Evidence from Tanzania," ACRN Journal of Entrepreneurship Perspectives, vol. 2, no. 1, pp. 31-59, 2013.

[10] W. C. Gomera, J. Suhonen, S. S. Oyelere and A. F. Kapinga, "Mobile Technology for Record Keeping by Women Entrepreneurs in Tanzania: User Requirement Assessment," in In International Conference on Social Implications of Computers in Developing Countries, Dar es Salaam, Tanzania, 2019.

[11] F. A. Kapinga, C. S. Monterp and R. E. Mbise, "Mobile technology for women entrepreneurs in Iringa, Tanzania: User requirements and architectural design," in AFRICON, Cape Town, South Africa, 2017.

[12] L. Dube' and G. Pare', "Rigor in Information Systems Positivist Case Research. Current Practices, Trends and Recommendations," Management Information System Quarterly Research Essay, vol. 27, no. 4, pp. 597 - 636, 2003.

[13] M. B. Charyya, Mobile Phone: A new tool to empower rural women in India with Special reference to Bulpur - Santiniketan, International Association of Women in Radio and Television (IAWRT), 2015.

[14] R. M. DeLancey, "Gendering Entrepreneurship and Technology: A mixed study of Retaolers in a Development Economy," vol. 2, no. 3, 2015.

[15] M. Joseph, "The Potential of ICTs to Empower Rural Women," in IST-Africa 2011 Conference, 2011.

[16] E. H. Diniz, M. Pozzebon, M. Jayo and E. Araujo, "The role of Information and Communication Technologies (ICT) in Improving Microcredit: The case of Correspondent Banking in Brazil," in PICMET, CApe Town South Africa, 2008.

[17] J. C. Aker and I. M. Mbiti, "Mobile phones and Economic Development in Africa," Journal of Economic Perspectives, vol. 24, no. 3, pp. 207 - 232, 2010.

[18] M. Komunte, "Usage of Mobile Tecgnology in Women Entrepreneurs. A case study of Uganda," The African Journal of Information Systems, vol. 7, no. 3, 2015.

[19] J. Kesanta and B. Andre, "Impact of Women Empowered through Community Savings Group on the Wellbeing of their Families: A Study from Mgubwe Tanzania," Interdisciplinary of Best Practices in Global Development, vol. 1, no. 1, 2015.

[20] H. Chipindula and J. E. Mwanga, "Assessing the role of Village Community Banks in social Empowerment of Women within households in rural communities of Mtwara District, Tanzania.," Research on Humanities and Social Sciences, vol. 5, no. 20, 2015.

[21] T. Milonge, "Empowering People through Community Banks (VICOBA); A Case of Simanjiro VICOBA Group Poultry Project in Sombetini Ward Arusha - Tanzania," Dissertation. The Open University of Tanzania, 2014.

[22] D. Fletschner and L. Kenney, "Rural Women's access to financial services credit, savings and insurance," Agricultural Development 
Economics Division: The Food and Agriculture Organization of the United Nation FAO, ESA working paper No. 11-07, 2011.

[23] R. Buchanan, "Wicked problems in design thinking," Design issues, vol. 8, no. 2, pp. 5-21, 1992.

[24] K. Dorst, "The core of 'design thinking'and its application," Design studies, vol. 32, no. 6, pp. 521-532, 2011.

[25] N. Cross, Design thinking: Understanding how designers think and work, New York: Oxford Berg, 2011.

[26] R. Razzouk and V. Shute, "What is design thinking and why is it important?" Review of educational research, vol. 82, no. 3, pp. 330348, 2012.

[27] T. Brown and J. Wyatt, "Design thinking for social innovation," Development Outreach, vol. 12, no. 1, pp. 29-43, 2010.

[28] E. Bjögvinsson, P. Ehn and P.-A. Hillgren, "Design things and design thinking: Contemporary participatory design challenges," Design issues, vol. 28, no. 3, pp. 101-116, 2012.

[29] S. S. Temu and E. K. Ishengoma, "Financial Linkages and Perfomance of Rural microfinance Cooperatives: Tanzania Case," Indian Journal of Economics and Business, vol. 9, no. 2, pp. 285 302, 2010.

[30] S. Khandker, G. Koolwal and N. Sinha, "Benefits of improving young women labor market opportunities: Evidence from Group based credit program in rural Bangladesh," World Bank Development Report, Bangladesh, 2008.

[31] M. Lindrert, D. Yazdanfar and H. Boter, "“"Perceptions of financial sources among women entrepreneurs in Tanzania"," African Journal of Economic and Management Studies, vol. 6, no. 2, pp. 197 - 218, 2015.

[32] J. Battilana and S. Dorado, "Building sustainable Hybrid Organizations: The case of Commercial Microfinance Organizations," Academy of Management Journal, vol. 53, no. 6, pp. 1419 - 1440, 2010.

[33] S. R. Khandker, A. M. Khalily and H. A. Samad, ""Seasonal and extreme poverty in Bangladesh: Evaluating an ultra-poor microfinance project"," World Bank Development Report, 2008.

[34] D. Hussain and M. Z. Yaqub, ""Micro - Entrepreneurs: motivations, success Factors and Challenges"," International research Journal of Finance and Economics, vol. 56, pp. 22-28, 2010.

[35] M. Alam and I. R. Molla, ""The limitation of microcredit for promoting microenterprises in Bangladesh," Economi annals, vol. 57, no. 192, pp. 41-53, 2012.

[36] U. Bhuiyan and A. Shah, ""A literature survey of value creation through relationship banking"," Africa Journal of Business Management, vol. 35, no. 5, pp. 13517 - 13522, 2011.

[37] S. Gibb, "Microfinance's impact on education, poverty and empowerment. A case study from Bolivian," Altiplanio Development Research working paper series, institute for advanced development studies, 2008.

[38] N. Kabeer, "Between affiliation and autonomy: Navigating pathways of women's empowerment and gender justice in rural Bangladesh," Development and change, vol. 42, no. 2, pp. 499-528, 2011.

[39] F. Girabi and A. E. G. Mwakaje, "Impact of Microfinance on smallholder farm productivity in Tanzania. The case of Iramba District," Asian Economic and Financial Review, vol. 3, no. 2, pp. 227 - 242, 2013.

[40] P. J. Salia and S. J. Mbwambo, "Does microcredit make any difference on borrowers' business? Evidence from a survey of women owned microenterprises in Tanzania," International Journal of Social Science and entrepreneurship, vol. 1, no. 9, pp. 431 - 444, 2014.

[41] X. Qin and B. O. Ndiege, "Role of financial Development in Economic Growth: Evidence from Savings and Credits Cooperative Societies in Tanzania," International Journal of Financial Research, vol. 4 , no. $2,2013$.
[42] N. Mori and D. Olomi, "The Effect of Broards on the Perfomance of Microfinance Institutions: Evidance from Tanzania and Kenya," REPOA - Policy Research for Development, 2012.

[43] H. Mahabub, "Credit for alleviation of rural povery," International Food Policy, 1988.

[44] C. Brindley, "Barriers to women achiving their antrepreneurial potential," International journal of Entrepreneurial Behavior and Research, vol. 11, no. 2, pp. 144 - 161, 2005.

[45] E. A. Bosompem, "Micro-Credit lending and Women's Empowerment: Experiance of Rural Kasoa Women," The Journal of Global Gender Studies, vol. 1, no. 1, 2013.

[46] J. Rumanyika, M. Tedre, M. Apiola, S. S. Oyelere and N. R. Mramba, "Contemporary Challenges in Street Trader-Customer Interaction Through Mobile Devices in Dodoma, Tanzania," in In International Conference on Social Implications of Computers in Developing Countries, Dar es Salaam, Tanzania, 2019.

[47] J. Donner and M. Escobari, "A review of the research on mobile use by micro and small entreprises (MSEs)," in International Conference on Information and Communication Technology and Development (ICTD), 2009.

[48] W. C. Gomera and A. Mikko, "Improve MFI-MB Interaction with Technology: an Explorative Study in Dar es Salaam, Tanzania," in IEEE, AFRICON 2015, Addis Ababa, 2015.

[49] C. A. Chair, Mobile Phone for Development: How have women in the informal sector used their mobile phone to enhance themselves and their business? Cape Town: University of Cape Town, 2012.

[50] C. Blair, "Women \& Mobile: A global opportunity. A study on the mobile phone gender gap in low and middle income countries," Foundation for Women, 2015.

[51] J. w. Creswell, Research Design - qualitative, quantitative and mixed methods approach 4th Edition, Croydon, CR04YY: CPI Group UK Ltd, 2014.

[52] G. Walsham, "Doing Interpretive Research," European Journal of Information System, vol. 15, pp. 320 - 330, 2006.

[53] J. N. Amaral, "About Computing Science Research Methodology," webdocs.cs.ualberta.ca/ c603/readings/research-methods.pdf.

[54] W. C. Gomera, G. Oreku, M. Apiola and J. Suhonen, "Mobile training in micro business: Design Science Research for Frugal Innovation," Cape Town. South Africa, 2017.

[55] S. Khavul, "“Microfinance: Crating Opportunities for the poor?" The academy of management Perspective, vol. 24, no. 3, pp. 58 - 72, 2010.

[56] L. P. Kyrgidou, "Developing women entrepreneurs' knowledge, skills and attitudes through e-mentoring support," Journal of Small Business and Enterprise Development, vol. 20, no. 3, pp. 548-566, 2013.

[57] K. Naser and R. W. Mohammed, "Factors that affect women entrepreneurs: Evidence from emerging economy," International Journal of Organization Analysis, vol. 17, no. 3, pp. 225-247, 2009.

[58] S. Shamsad, "Social - economic dynamics of microcredit programs in informal settlements: The case of Khulna City, Bangladesh," HKU Theses, Bangladesh, 2008.

[59] D. Roodman and J. Marduch, "The impact of microcredit on the poor in Bangladesh - Revising evidence," Center of Global Development Working paper 174, June 2009.

[60] S. Afrin, I. Nazrul and U. A. Shahid, ""A multivariate model of micro credit and rural women entrepreneurship development in Bangladesh," International Journal ofBusiness and Management, vol. 3, no. 8, 2008.

[61] D. Kumar, A. Hossain and M. C. Gope, "Role of micro credut programme in empowering rural women in Bangladesh: A study on Grameen Bank Bangladesh limited," Asian Business Review, vol. 3, no. $6,2013$.

[62] https://www.tcra.go.tz/images/headlines/TelCom Statistics March_2 